\title{
Escrita: tecer e esculpir o texto
}

\author{
Writing: weaving and carving the text
}

Escritura: Tecer y esculpir el texto

Luís Barbeiro $\odot$

Escola Superior de Educação e Ciências Sociais, Instituto Politécnico de Leiria, Leiria, Portugal.

$$
\diamond
$$

\section{RESUMO}

As palavras de um texto não se encontram pré-determinadas. Quem escreve realiza escolhas entre as possibilidades disponibilizadas pela língua. $\mathrm{O}$ desenvolvimento linguístico traz consigo o alargamento de recursos lexicais, sintáticos, semânticos e textuais. Esse desenvolvimento traça um caminho mais direto para o texto ou ativa em maior grau a consideração de escolhas e decisões por parte do sujeito, enquanto escreve? O presente estudo analisou a evolução das componentes de formulação e reformulação no processo de escrita de alunos do ensino básico português. Os dados provêm da interação entre alunos de diferentes anos (do $2^{\underline{O}}$ ao $8^{\circ}$ ), organizados em pequenos grupos, para escreverem um texto colaborativamente. A análise incidiu sobre as operações de formulação/reformulação realizadas. Os resultados mostram um alargamento das possibilidades consideradas, ao longo do processo de construção do texto, dos anos iniciais para os anos mais avançados. Esse movimento alerta para a necessidade de reforçar a capacidade de reescrita e reformulação na aprendizagem da escrita.

Palavras-chave: Escrita. Processo de escrita. Reformulação. Operações. Escolha.

\begin{abstract}
The words of a text are not predetermined. The writer makes choices among the possibilities offered by the language. Linguistic development brings with it the increase of lexical, syntactic, semantic, and textual resources. Does this development draw a more direct path to the text, or does it activate a higher level of choices and decisions during writing? The current study analysed the evolution of the components of formulation and reformulation in the writing process of students attending Portuguese basic education. The data comes from the interaction between students of different years (2nd to 8 th), organized in small groups, to write a text collaboratively. The analysis focused on the formulation/reformulation operations carried out during text construction. The results show an expansion of the possibilities considered, from the initial school years to the more advanced levels. This movement implies the need to reinforce the ability to rewrite and reformulate, in learning to write.
\end{abstract}

Keywords: Writing Writing process. Reformulation. Operations. Choice.

\section{RESUMEN}

Las palabras de un texto no se encuentran predeterminadas. Quien escribe elige entre las posibilidades que la lengua ofrece. El desarrollo lingüístico trae consigo la ampliación de los recursos léxicos, sintácticos, semánticos y textuales. ¿Este desarrollo traza un camino más directo al texto o activa en mayor grado la consideración de elecciones y decisiones por parte del sujeto mientras escribe? Este estudio examinó la evolución de los componentes de la formulación y reformulación en el proceso de escritura de los estudiantes de educación básica portuguesa. Los datos provienen de la interacción entre alumnos de diferentes años (del 20 al $8^{\circ}$ ), organizados en pequeños grupos, para escribir un texto colaborativamente. El análisis se centró en las operaciones de formulación / reformulación realizadas. Los resultados muestran un incremento de las posibilidades consideradas a lo largo del proceso de construcción del texto de los años iniciales para los años más avanzados. Este movimiento alerta a la necesidad de reforzar la capacidad de reescritura y reformulación en el aprendizaje de la escritura.

Palabras clave: Escritura. Proceso de escritura. Reformulación. Operaciones. Elección. 


\section{Introdução}

As comparações com "tecer" e "esculpir" têm sido utilizadas para descrever ou ilustrar a atividade de escrever um texto. Os fundamentos destas imagens podem ligar-se à necessidade de o processo de escrita assegurar a construção de um texto e ao facto de o escritor escrever o texto antes de este ser apresentado perante o leitor. Este facto permite-lhe não se limitar à "formulação" de unidades discursivas para alimentar o fio textual, como se se tratasse de um fio discursivo semelhante à oralidade, mas também proceder à "reformulação" dessas unidades, que vão surgindo na sua mente e, eventualmente, no papel ou no ecrã, procedendo à seleção do que vai aparecer, posteriormente, perante o leitor.

Podemos ligar as componentes de formulação e reformulação ao que Britton (1994; 1980) expressa no seu texto clássico intitulado "Shaping at the point of the utterance". Neste texto, James Britton parte, precisamente, da analogia de escrever com a atividade de esculpir, com base no que Perl e Egendorf (1979) designam de "estruturação retrospetiva" (retrospective structuring). Este procedimento é acompanhado por "descoberta" (discovery), "estruturação projetiva" (projective structuring) ou, nas palavras de Britton, "moldagem do texto à medida que este vai avançando" (shaping at the point of the utterance):

\begin{abstract}
'Quando observados de perto, os alunos parecem escrever indo e voltando entre o que eles queriam dizer e as palavras na página, e considerando novamente o que têm na sua mente'. Este é, em essência, o processo que eles chamam de 'estruturação retrospectiva' e a sua quase inevitabilidade pode ser afirmada comparando a escrita à escultura: o escultor com o cinzel na mão deve cortar e observar o efeito do seu corte antes de prosseguir. Mas a estruturação retrospectiva precisa de ser acompanhada pelo que os autores designam de 'estruturação projetiva', moldando o material de tal maneira que o significado pretendido pelo escritor seja transmitido ao leitor que tem em mente (BRITTON, 1994, p. 150).
\end{abstract}

Podemos associar esta segunda componente à outra imagem mencionada acima, "tecer", a qual também tem sido utilizada por muitos autores, para se referirem à escrita e salientarem a ligação etimológica de "texto" a "tecido". É o que faz Roland Barthes, por exemplo, em Barthes (1977, p. 159, tradução nossa), ao considerar o texto como um "tecido de significados", relembrando que "etimologicamente, o texto é um tecido, um pano tecido"2 (1977, p. 159, tradução nossa).

\footnotetext{
1 Do original: weave of signifiers.

2 Do original: etymologically, the text is a tissue, a woven fabric.
}

Ao colocarmos em foco o processo de escrita, a perspetiva que emerge não é a do "tecido", mas a própria atividade de "tecer", tomada aqui sobretudo na componente de assegurar a continuidade do fio textual, ou seja, o texto vai avançando, implicando a junção de novos elementos que o prolongam até atingir o final. A comparação poderia ser diretamente estabelecida com a atividade de "tecer" um cordel ou baraço, juntando novos segmentos, por exemplo, de feno, como acontecia na atividade agrícola tradicional. Mas, enquanto a atividade de tecer essa corda apenas implicava ir juntando novos elementos aos anteriores, entrelaçando-os com eles, a escrita do texto implica também dar forma, moldar, esculpir cada segmento. Por sua vez, o escritor enquanto escultor necessita de "ir produzindo" ou de "ir trazendo" para o processo, à medida que escreve, o próprio material (linguístico) a esculpir. Poderíamos retomar ou recuperar aqui a analogia com o tecelão (PINTO, 2016) que vai escolhendo os fios; mas, mesmo depois de escolhidos e integrados na escrita, pode haver reformulação/reescrita por isso, a imagem do tecelão, por si só, não é bastante, se não incluirmos a possibilidade de reformulação, à medida que o texto vai sendo construído.

Deste modo, considerando esta coexistência entre as duas componentes, tomamos como ponto de partida neste texto a perspetiva de Britton (1994) e de Perl e Egendorf (1979), que assinalam a complementaridade dos dois subprocessos: o que corresponde a gerar o fio de palavras para que o texto tenha continuidade; e o que corresponde a modelar o próprio texto, a procurar a melhor forma que deve ter por meio das palavras.

Ao contrário do que pode entender-se das palavras de Perl e Egendorf (1979), não limitamos o segundo subprocesso ao que já se encontra escrito na página. A atividade de modelar pode acontecer antes e a acompanhar essa inscrição na página, como evidenciam as propostas que emergem na interação entre os participantes na escrita colaborativa (BARBEIRO, 1999; 2001). No mesmo sentido, tendo também por base a escrita colaborativa, Calil (2016) contrapõe às rasuras na página ou "rasura escrita", as "rasuras orais", para se referir às modificações evidenciadas nos diálogos da escrita colaborativa a pares, mesmo em relação a porções textuais que ainda não foram escritas. O subprocesso de modelar o texto não se limita ao movimento retrospetivo (de maior ou menor alcance) associado à revisão. Associamo-lo também à procura da forma a dar ao texto que vai sendo construído. Podemos, também, aqui estabelecer o contraste, por meio de uma comparação: ao contrário de uma linha de salsichas todas iguais, que vai saindo em fio, o fio textual vai produzindo unidades diferentes, sujeitas à procura $\mathrm{e}$ à decisão sobre as palavras que as constituem. As duas componentes correspondem assim, noutra designação, a 
uma componente de "formulação" e a uma componente de "reformulação".

O percurso de desenvolvimento da escrita pode trazer alterações quanto à presença e à ação destas componentes. Cada uma delas aponta para estratégias didáticas e pedagógicas diferenciadas. Interessa, por conseguinte, conhecer esse desenvolvimento em relação ao seu peso e ação, a fim de orientar a direção a dar ao ensino da escrita para promover o seu desenvolvimento.

Os estudos sobre a evolução da competência de escrita têm evidenciado uma maior capacidade de revisão que incide sobre aspetos de maior profundidade, no caso dos escritores com uma escrita mais desenvolvida. Esse movimento retrospetivo pode ter lugar na parte final do processo, após a escrita de uma primeira versão, ou ainda no seu decurso, implicando alterações de rumo associadas à recursividade (HAYES; FLOWER, 1980; BARBEIRO, 1999; 2003). Este nível de maior globalidade, respeitante a todo o texto ou a unidades maiores do texto, é o que frequentemente se encontra expresso nos modelos do processo de escrita (HAYES; FLOWER, 1980; HAYES, 1996). No entanto, até se atingir este nível, não existe apenas a componente de geração a atuar. Como estabelecemos a componente de modelação ou reformulação a acompanhar a formulação ou geração, interessa verificar de que maneira a reformulação está presente e se existe evolução quanto ao seu peso e à maneira como é ativada e gerida no percurso de desenvolvimento.

A observação de perto do processo, como a que é proporcionada pelos registos de escrita colaborativa, permite ter acesso à manifestação das duas componentes. A análise da progressão e da interação permite apreender a sua presença a par e par da construção textual, em relação a unidades elementares como frases ou até palavras.

\section{Objetivos}

Uma questão que emerge é a relativa à conjugação destas duas componentes com o desenvolvimento da escrita. Trata-se de uma evolução que resolve cada vez mais diretamente os problemas de formulação, diminuindo o recurso à reformulação, tomada como um "remendo", ou seja, uma "reparação" resultante de uma imperfeição processual? Ou trata-se de uma evolução que encontra potencialidades na própria existência da componente de reformulação?

Este texto tem como objetivo primordial observar o sentido da evolução, a partir da observação da escrita colaborativa. As propostas de modelos têm procurado captar diferenças entre a atividade escritural de adultos ou escritores hábeis e a escrita de escritores aprendentes (SCARDAMALIA; BEREITER, 1987; BERNINGER;
SWANSON, 1994; KELLOG, 2008; HAYES, 2012). Os diagramas correspondentes aos modelos de Bereiter e Scardamalia (1987) ou de Hayes $(2011 ; 2012)$ pretendem dar conta do percurso de geração do texto. Em relação a esses modelos, a observação dos registos de interação entre os participantes na escrita colaborativa permite aceder a níveis de maior especificidade, quanto às unidades que vão sendo geradas e quanto às operações que as fazem surgir, colocando em evidência as componentes de formulação e reformulação em relação a essas unidades. A compreensão do desenvolvimento do processo de escrita, segundo esse nível de maior especificidade, permite estabelecer como objetivos adicionais orientar a ação didática no sentido de promover as componentes ou atividades que favoreçam a colocação em ação das competências associadas a uma escrita mais desenvolvida.

\section{Metodologia}

\section{Instrumentos}

O instrumento utilizado neste estudo para aceder ao processo consistiu na tarefa de produção em grupo do relato ficcionado por parte de três amigos de uma visita a Leiria, a cidade dos alunos que participaram no estudo. A tarefa de escrita em grupo constitui uma tarefa natural e que ocorre em sala de aula. No nosso estudo, foi utilizada por dar acesso a processos mentais do escrevente ligados à geração do texto e à decisão sobre o texto. Apesar de não constar entre os métodos de pesquisa mencionados por Hyland (2016), constitui um método que dá acesso a dados captados enquanto observação exterior e a dados que, alternativamente, só se tornariam acessíveis por introspeção, eliminando a desvantagem de diferimento temporal ou de artificialidade ligada aos métodos introspetivos.

A realização da tarefa foi objeto de registos em áudio e vídeo, o que possibilitou a posterior transcrição da interação entre os elementos do grupo. Os textos produzidos também foram recolhidos para análise.

\section{Procedimentos}

Participaram do estudo 96 alunos do ensino básico, 24 de cada um dos seguintes níveis de escolaridade: $2^{2}$, 4 o, $6^{\circ}$ e $8^{\circ}$ anos. A distribuição por sexo é igual em cada nível de escolaridade, perfazendo, no total, 48 rapazes e 48 raparigas. As idades médias dos participantes nos diferentes níveis de escolaridade eram de $7 ; 10,9 ; 10 ; 11,9$ e 14;0, respetivamente para o segundo, quarto, sexto e oitavo anos de escolaridade. $\mathrm{O}$ estudo foi realizado em escolas da cidade de Leiria. Os alunos viviam na cidade ou arredores, mas todos frequentavam escolas nessa cidade. 
Os grupos foram constituídos dentro de cada turma. A seleção dos elementos para trabalharem em conjunto em um grupo foi feita ao acaso, por meio do preenchimento de uma tabela, na qual estava prevista a participação de um número igual de elementos de cada sexo e o requisito de que os grupos deveriam ser mistos. Em relação ao nível de desempenho escolar, respeitou-se também a diversidade existente nas turmas, apenas foram afastados da possibilidade da inclusão no estudo os casos em que o nível de desenvolvimento da escrita impedia a construção de um texto de forma autónoma. O investigador deslocouse às escolas para conduzir a realização da tarefa e os respetivos registos.

No início da tarefa, os participantes receberam uma folha com os nomes dos protagonistas (João, Rui e Lena). Também receberam um conjunto de seis postais ilustrados de Leiria para os ajudar a gerar conteúdo. Com estes elementos, deveriam escrever um texto que contasse a visita a Leiria dessas personagens. O texto deveria ser criado em conjunto, ou seja, deveriam escrever um único texto em grupo, discutindo, colaborando e chegando a acordo entre si, e não versões individualizadas. Por outro lado, cada elemento do grupo recebia uma folha de rascunho na qual deveria ir escrevendo o texto, ou seja, todos os participantes eram confrontados com a tarefa de redação e confrontado com as respetivas exigências, designadamente no domínio da ortografia.

A tarefa foi realizada em uma sala da escola, para a qual os alunos se deslocaram, a fim de trabalharem em grupo e para permitir a realização dos registos. Para proporcionar a habituação à presença da câmara, a atividade começou com uma entrevista ao grupo, conduzida pelo investigador, acerca da sua relação com a disciplina de Língua Portuguesa, nomeadamente sobe a relação com a leitura e a escrita.

Uma vez realizados os registos, estes foram objeto de transcrição. A análise subjacente aos resultados aqui apresentados implicou: a identificação das operações de (re)formulação textual, a contabilização quer das palavras do texto, quer das palavras que foram sendo consideradas como suscetíveis de integrarem o texto, em resultado dessas operações, a verificação da manutenção ou não no texto final das palavras que iam sendo propostas.

Em relação às operações de (re)formulação, consideramos as categorias de adição, supressão, deslocamento e substituição. Para a consideração e contabilização de uma operação, aplicámos o requisito de possibilidade de existência autónoma das unidades envolvidas, ou seja, não considerámos como operações as formulações que consistiam no completamento de unidades já iniciados em um momento anterior, mas que tinham ficado incompletas (por exemplo, tendo por base o enunciado "visitaram o castelo", a reformulação para "visitaram o castelo de
Leiria" conta apenas como uma operação, mesmo que a proposta tenha surgido em dois momentos: 1) "visitaram o castelo de"; e 2) "visitaram o castelo de Leiria").

A "adição" consiste na modificação por junção de uma unidade linguística a um estado textual pré-existente. No caso da operação de adição, estando em causa neste texto, as dimensões de formulação e reformulação, considerámos de forma específica o que designámos como "propostas-base" $(P-b)$ ou propostas de base e as operações subsequentes, que também podem ser de adição. As propostas-base consistem nas adições que aparecem no processo em momentos charneira, logo no início da construção do texto ou seguindo-se à fixação por escrito do enunciado anterior e servindo de base a propostas de reformulação para que se venha a fixar novo enunciado. Segundo o critério de possibilidade de existência autónoma enquanto unidade linguística no contexto em que surgem, consistem em frases ou, no caso dos títulos, também podem consistir em sintagmas nominais. Se não atuasse a componente de reformulação, o texto resultaria da concatenação destas propostas de base. Assim, nas propostas-base pode considerar-se em evidência a dimensão de "formulação".

A "supressão" consiste na modificação de um estado textual por apagamento de uma unidade linguística.

O "deslocamento" consiste na modificação da ordem sequencial entre unidades linguísticas.

A "substituição" consiste na modificação da unidade linguística que ocupa uma determinada posição sequencial ou estrutural por permuta ou troca com uma outra.

A comparação entre os grupos (níveis de escolaridade) tomou como indicadores os valores médios alcançados por cada variável dependente. Aplicaramse testes estatísticos, por meio do software de análise estatística SPSS (versão 23), para verificar a existência de diferenças significativas entre os grupos. Recorreu-se à aplicação de um modelo ANOVA one-way e a testes de comparações múltiplas (teste de Scheffé ou teste de Tamhane, no caso de inexistência de igualdade de variâncias) para identificar diferenças significativas entre os valores apresentados pelos diferentes grupos. Para aplicação do modelo ANOVA, procedeu-se à verificação das condições da sua aplicabilidade, quanto à distribuição normal (por meio do teste de Kolmogorov-Sminorv) e quanto à homogeneidade de variância (por meio do teste de Levene). Nos casos em que essas condições não se verificaram, recorreu-se ao teste não paramétrico de Kruskall-Wallis (MARÔCO, 2011).

\section{Resultados}

\section{Apresentação}

Se a componente de reformulação não estivesse atuante, o texto final seria resultante apenas da transcrição 
das propostas-base que iam sendo adicionadas à medida que se avança no texto. Na verdade, após a formulação de elementos destas propostas (ou de outras), estes elementos ficam sujeitos à formulação de novas propostas que os alteram por meio de operações de reformulação consistindo em adições, supressões, deslocamentos e substituições. Por sua vez, as novas propostas continuam a ser alvo das operações de reformulação.

Em consequência, a formulação correspondente à primeira proposta (a proposta-base) pode encontrar-se muito alterada no texto final. Na Tabela 1, apresentamse os valores correspondentes às palavras surgidas nas propostas-base para a construção dos diversos segmentos do texto. Indicam-se a média de palavras geradas nessas propostas para cada nível de escolaridade, a relação com o total de palavras geradas no decurso do processo, as médias correspondentes ao número dessas palavras que se mantêm no texto final e à proporção face ao número de palavras do texto.

Tabela 1 - Palavras geradas nas propostas de base

\begin{tabular}{cccc}
\hline Nível & Geradas nas P-b & \% / Pal. geradas & \% / Pal. do texto \\
\hline 2ㅇ ano & 52,2 & 43,4 & 42,7 \\
4ㅇ ano & 75,6 & 25,4 & 30,7 \\
6o ano & 73,4 & 14,4 & 16,9 \\
8o ano & 101,2 & 13,6 & 15,1 \\
\hline
\end{tabular}

Fonte: Elaboração própria.

As diferenças significativas entre os níveis de escolaridade que se encontram no número de palavras geradas nas propostas-base $(\mathrm{F} 3,28=4,814, \mathrm{p}=, 008$, com diferenças significativas entre o segundo e o oitavo ano pelo teste de Scheffé) podem ser associadas à extensão textual, pois os textos mais longos também têm tendencialmente um maior número de propostas de base.

Mostram-se também significativos e relevantes os valores proporcionais pelo que revelam da força assumida pela componente de reformulação: no caso da proporção em relação ao total de palavras geradas, existe uma progressão decrescente e, no oitavo ano, apenas $13,6 \%$ das palavras consideradas para a construção textual foram geradas nas propostas de base; de modo paralelo, em relação às palavras presentes no texto final, existe também uma progressão decrescente que leva a que, no oitavo ano de escolaridade, apenas $15 \%$ das palavras do texto tenham sido geradas em propostas de base, tendo a restante proporção $(85 \%)$ sido gerada por ação das propostas de reformulação. Os valores dos testes estatísticos confirmam a significância destes contrastes $\left(\mathrm{K}-\mathrm{W} \chi^{2}=9,254, \mathrm{p}=0,026\right.$, para a percentagem de palavras geradas nas propostas de base, com diferenças significativas entre o segundo e os restantes anos de escolaridade, pelo teste de Tamhane; F3,28=8,391, p=,000, para a percentagem de palavras geradas nas propostas de base que são mantidas no texto final, sendo significativas as diferenças entre o 2, o 6ㅇ e o $8^{\circ}$ ano, pelo teste de Scheffé).

As operações de (re)formulação textual distribuem-se por diferentes categorias, que não apresentam o mesmo peso para a construção do texto, como se pode verificar na Tabela 2. O processo de escrita é sobretudo marcado pelas operações de adição e de substituição. As operações de deslocamento e de supressão apresentam uma frequência bastante inferior.

A operação de adição (considerando o valor global das propostas-base e de outras adições seguintes) e a operação de substituição têm comportamentos inversos, com a progressão na escolaridade. No segundo ano, a operação de adição representa mais de $50 \%$ das operações, enquanto a operação de substituição representa cerca de 36\%. No oitavo ano, estes valores encontram-se invertidos, cabendo à operação de substituição mais de metade do número de operações e tendo a adição um valor próximo de $36 \%$. Para além das diferenças significativas em termos absolutos $(\mathrm{F} 3,28=27,070, \mathrm{p}=, 000$, para a adição, e $\mathrm{F} 3,28=35,381$, $\mathrm{p}=, 000$, para a operação de substituição), também são significativos os contrastes quanto aos pesos proporcionais entre estas operações $(F 3,28=9,516, p=, 000$, para a adição, e F3,28=8,407, p=,000, para o peso da substituição). Os contrastes significativos encontram-se entre o $2^{\mathrm{O}}$ e os níveis do $6^{\underline{O}}$ e $8^{\circ}$ anos (teste de Scheffé).

As outras operações, supressão e deslocamento, para além de menos frequentes, apresentam contrastes menos pronunciados e significativos. Na operação de supressão, as diferenças significativas encontram-se apenas para os valores absolutos $(\mathrm{F} 3,28=30,900, \mathrm{p}=, 0000$, face a $\mathrm{K}-\mathrm{W} \chi^{2}=4,670, \mathrm{p}=0,198$, para os valores percentuais). A operação de deslocamento não apresenta diferenças significativas $\left(\mathrm{F} 3,28=2,521, \mathrm{p}=, 078\right.$, e $\mathrm{K}-\mathrm{W} \chi^{2}=1,300$, $\mathrm{p}=0,729$, para os valores percentuais).

Tabela 2 - Categorias de operações de (re)formulação textual

\begin{tabular}{|c|c|c|c|c|c|c|c|c|c|}
\hline \multirow{2}{*}{ Ano } & \multirow{2}{*}{ Média Pb } & \multicolumn{2}{|c|}{ Adição } & \multicolumn{2}{|c|}{ Supressão } & \multicolumn{2}{|c|}{ Substituição } & \multicolumn{2}{|c|}{ Deslocamento } \\
\hline & & Média Seg. & $\mathrm{Pb}+$ Seg $\%$ & Média & $\%$ & Média & $\%$ & Média & $\%$ \\
\hline $2^{o}$ & 8,3 & 19,1 & 53,5 & 5,0 & 8,0 & 19,1 & 35,6 & 2,0 & 2,8 \\
\hline $4^{\circ}$ & 11,6 & 42,3 & 44,4 & 9,5 & 7,5 & 60,0 & 45,9 & 2,5 & 2,2 \\
\hline 60 & 13,0 & 74,8 & 42,6 & 18,8 & 8,8 & 99,3 & 46,3 & 4,9 & 2,3 \\
\hline $8^{\circ}$ & 14,9 & 94,9 & 36,0 & 29,8 & 10,1 & 156,1 & 52,4 & 4,9 & 1,6 \\
\hline
\end{tabular}

Fonte: Elaboração própria. 


\section{Discussão}

A análise do processo de escrita com base no registo das atividades e na interação que têm lugar durante a escrita colaborativa evidencia que a dimensão de reformulação desempenha um papel relevante. Esse papel acentua-se entre o $2^{\circ}$ e o $8^{\circ}$ ano de escolaridade. A intervenção da reformulação não desempenha apenas uma função de reparação em termos de conteúdo ou de expressão linguística (ao lado da correção de erros linguísticos e formais), mas podemos considerar que se encontra no cerne do próprio desenvolvimento da escrita. Se o seu papel fosse apenas de reparação, seria de esperar que a sua intervenção se fosse reduzindo com o crescimento dos sujeitos e a progressão na escolaridade e o correspondente desenvolvimento linguístico. Pelo contrário, a sua intervenção apresenta um incremento, o qual associamos a potencialidades para os escreventes alcançarem níveis mais elevados de produção de textos e modelos mais elaborados e complexos para o desempenho das tarefas de escrita.

As propostas de modelos de processos de escrita têm procurado captar diferenças entre o modo de desempenho de adultos ou escritores hábeis e o de escritores aprendentes (SCARDAMALIA; BEREITER, 1987; BERNINGER; SWANSON, 1994; KELLOG, 2008; HAYES, 2012). Os modelos são importantes para a compreensão de um determinado estado de desenvolvimento da escrita e dos processos que lhe são característicos. Contudo, a construção de modelos adota níveis de "generalidade" e de "generalização" que podem "esconder" alguns aspetos relevantes para a compreensão do desenvolvimento da escrita. As diferenças apresentadas pelos modelos têmse situado ainda em um nível de generalidade que não dá conta de microprocessos ligados à geração do texto, ou seja, à formulação das unidades linguísticas que vão sendo elaboradas para serem inseridas ou não no texto. As unidades de base desses modelos são tomadas como um todo, sem se considerar os microprocessos que podem estar presentes na sua elaboração. Por outro lado, a procura de construção do modelo obriga a adotar um nível de generalização que afasta a manifestação de microprocessos que podem ser detentores de potencialidades para explicar a progressão do desenvolvimento.

Bereiter e Scardamalia (1987) contrapõem o modelo de "exposição do conhecimento" (knowledge telling) ao modelo de "transformação do conhecimento" (knowledge transforming). A estratégia de exposição do conhecimento caracteriza-se pela colocação ou formulação no texto das ideias relativas ao tópico da tarefa, à medida que vão sendo recuperadas da memória, "sem qualquer reorganização ou reformulação" (without any reorganization of the text's conceptual content or linguistic form), como explicitam
Alamargot e Fayol (2009). Esse modelo caracteriza a escrita dos escreventes nas fases iniciais (embora também possa ser adotado mais tarde, para a realização de determinadas tarefas de escrita, por escritores adultos). O modelo de transformação do conhecimento inclui os processos de exposição do conhecimento, para a geração ou formulação do texto, mas subordinam essa formulação à procura da solução mais adequada, tendo em conta a dialética entre a vertente do conteúdo (that which must be said) e a vertente retórica (that which can be said, to whom and in what way). O modelo de transformação do conhecimento é ativado de forma mais frequente a partir da adolescência e ao longo da idade adulta. Para promover a passagem do modelo de exposição do conhecimento para o modelo de transformação do conhecimento, Bereiter e Scardamalia (1987) propõem a adoção de estratégias de "facilitação processual" e de "concretização de objetivos".

Os resultados da nossa análise levam-nos a atribuir um papel relevante à dimensão de reformulação para a passagem do modelo de "exposição de conhecimento" (knowledge telling) para o modelo de "transformação do conhecimento" (knowledge transforming). A decisão e escolha implicadas pela existência de alternativas para a formulação linguística que pode ser adotada no texto levam a considerar o que dizer e o como dizer, abrindo caminho para a dialética entre a vertente de conteúdo e a vertente retórica. $\mathrm{O}$ estudo das justificações poderá permitir lançar luz sobre a manifestação dessas vertentes no percurso para se atingir um modelo mais desenvolvido. A interação que emerge da escrita colaborativa é abundante na presença dessas justificações e fundamentação das propostas de reformulação. Neste artigo, não havendo espaço para a sua análise alargada e em profundidade, apresentamos dois exemplos do $2^{2}$ e do $4 \underline{0}$ ano de escolaridade em que emerge a procura da solução mais adequada. No exemplo (1), está em foco o conteúdo: o aluno S28 propõe inicialmente a inclusão no relato da visita do evento "foram a um café"; contudo, altera a sua posição afastando esse conteúdo, por não ser relevante ("não têm nada!") e não se adequar ("não/ não faz jeito aqui"); o aluno S29, também em relação ao conteúdo, apresenta a possibilidade e procura a confirmação com os colegas de poderem recorrer a eventos imaginados, para o desempenho da tarefa.

(1) [4ㅇ ano, Grupo 10]

S28: foram a um café/ \{risos\} não têm nada!/ não/ não faz jeito aqui/ hum/

S29: a/ a gente também pode inventar/ não pode?/ então/ e isto/ depois

Em (2), o foco incide sobre a vertente retórica (estilística), logo no segundo ano de escolaridade. Na vertente 
retórico-estilística, surge em foco, desde bastante cedo, logo no segundo ano de escolaridade, a preocupação em evitar a repetição, razão também encontrada por Spinillo (2015), em níveis de escolaridade precoces. Neste caso, tratando-se da escrita de um texto do género relato, que exige a sequenciação de eventos, está em causa repetição da palavra "depois", o que leva à sua substituição por "a seguir".

(2) [2o ano, Grupo 4]

S11: depois/ ah!/ mas é sempre depois!

S12: pois é/ a seguir

S11: pois/ al a seguir!

S10: de/pois!/ eu já escrevi de...

S11: a seguir/ a seguir

No percurso de desenvolvimento, para lá do estádio correspondente ao modelo de knowledge transforming, Kellog (2008) propõe o estádio que designa knowledge crafting. Este é um estágio só atingido por alguns adultos, para quem a escrita assume um caráter profissional, e que exige cerca de duas décadas de prática, segundo Kellog (2008). O traço mais saliente deste estágio é a capacidade de considerar o ponto de vista do leitor, ou seja, exige a capacidade de articular o texto, o conhecimento e o leitor. Para Kellog (2008), os primeiros dez anos de prática de escrita corresponderiam ao estágio de knowledge telling, em que a escrita se encontra centrada no escritor. A segunda década de desenvolvimento dá acesso ao estágio de knowledge transforming, caracterizado pela interação entre os polos do escritor e do texto, seguindo-se, para a escrita profissional, o acesso ao macroestágio de knowledge crafting.

Defendemos, neste artigo, a existência de um percurso de desenvolvimento, em que a dimensão de reformulação promove a tomada de consciência de aspetos relativos ao texto e ao leitor (BARBEIRO, 2011). Os primórdios desse percurso, mesmo em relação à perspetiva do leitor, não se encontram apenas no nível do modelo knowledge transforming, mas são extensivos aos primeiros dez anos de prática de escrita, em que, ainda que de forma limitada, a perspetiva do leitor pode ser ativada em relação a aspetos formais, como as consequências da caligrafia ou do tamanho da letra (3) e em relação à gestão de conteúdos implícitos ou explícitos (4). Em (3), o aluno S4 defende que o colega S5 deve escrever com letra maior para que o leitor (o investigador) consiga ler:

(3) [2ㅇano, Grupo 2]

S5: eu não escrevo uma letra muito grande

S4: então mas deves es.../ e depois como é que o senhor vai conseguir?

S6: ler?
S4: ler assim as coisas?

S6: a minha/ a minha lê-se bem ///

Em (4), a alternativa consiste em escrever apenas "museu" ou tornar explícito que se trata de um museu de carros, sendo invocada a (in)compreensão do leitor para justificar um maior nível de explicitação:

(4) [4을 ano, Grupo 10]

S29: museu /

S30: dos carros/assim/ as pessoas pensam que é um museu de quê?

O aparecimento destes episódios mostra que a escrita surge como uma atividade de escolha (O'DONNELL, 2013), de tomada de decisão entre possibilidades alternativas, que constituem a dimensão de reformulação, desde cedo. Essas possibilidades vão se complexificando com o alargamento dos recursos linguísticos e textuais. A atenção a essa dimensão pode criar pontes ou passagens entre os modelos progressivamente mais complexos.

Como Bereiter e Scardamalia (1987, p.29) defendem, a função dos modelos, apresentados com um caráter discreto, não é dar conta de um continuum de variação, mas captar as características nucleares em que assentam as diferenças de abordagem do processo de escrita. Como dissemos, a construção de modelos adota, assim, níveis de "generalidade" e de "generalização" que evidenciam essas características nucleares, as quais podem ser depois complexificadas para dar conta da variabilidade do mundo real. As duas perspetivas são importantes: a evidenciação de características contrastantes, mas também a especificação e captura da variabilidade e da complexidade, para que o nível de "generalidade" e de "generalização" do modelo não escondam aspetos específicos relevantes que podem estar associados ao desenvolvimento da escrita.

As diferenças apresentadas pelos modelos situam-se em um nível que não dá conta de microprocessos ligados à geração do texto, à formulação das unidades linguísticas que vão sendo elaboradas para serem inseridas ou não no texto. As unidades de base desses modelos são tomadas como um todo, sem se considerar os microprocessos que podem estar presentes na sua elaboração. Por outro lado, a procura de construção do modelo obriga a adotar um nível de generalização que afasta a manifestação de microprocessos que podem ser detentores de potencialidades para explicar a progressão do desenvolvimento.

Berninger e Swanson (1994) propõem modificações ao modelo de Hayes e Flower (1980), para dar conta do processo dos escreventes principiantes e em desenvolvimento. Algumas dessas modificações 
consistem na inclusão de componentes mais específicas, como a transformação de ideias em linguagem na memória de trabalho ( "text generation") e a sua inscrição na página ("transcription"), no âmbito da componente geral da redação ( "translation"). Contudo, não preveem uma componente dedicada à reformulação, atuante no decurso da geração de texto ou da sua transcrição.

Nos modelos que dão conta da progressão na construção do texto, designadamente em relação à estratégia de knowledge telling (BEREITER; SCARDAMALIA, 1987; HAYES, 2011; 2012), a reformulação - que se manifesta por meio de microprocessos ligados às operações de adição (para além das propostas de base, que vão sendo objeto de propostas de alteração), substituição, supressão e deslocamento - não se encontra prevista. No modelo de Bereiter e Scardamalia (1987), o papel de pivô é atribuído à recuperação de conteúdo a partir da memória (Retrieve content from memory using probes). A partir dessa ativação, é avaliada a sua adequação (Run tests of appropriateness) e, conforme a passagem ou não na avaliação, o processo prossegue para o ato de escrever ou recua para a sondagem/ativação de novo conteúdo. Em relação ao ato de escrever em si, também não se encontra prevista ou incluída no modelo a ação da componente de reformulação (para além da recursividade devida à falha na ativação do conteúdo).

De modo similar, no modelo de Hayes (2011; 2012), conjunto de modelos específicos correspondentes a diferentes tipos de texto de knowledge telling, os segmentos textuais, que fazem avançar a construção do texto, os "comments", são submetidos, como um todo, no modelo, à avaliação da sua relação com o tópico, que faz recuar ou prosseguir, mas não são alvo da ação de uma componente de reformulação, que as operações de (re)formulação colocaram em evidência nos resultados do nosso estudo.

O que defendemos neste texto é a consideração de uma componente de (re)formulação que pode incidir sobre unidades de alcance variado, desde uma palavra, até a frase ou blocos de frases, e que torne manifestas as operações de reformulação que podem ter, e muito frequentemente têm, lugar após no seguimento da formulação da unidade inicial para gerar um novo segmento de texto. Essa componente de (re)formulação pode ativar critérios de conteúdo ou de expressão linguística para desencadear as operações e proceder a escolhas. A componente de reformulação atua ao longo do processo a acompanhar a geração de ideias e de texto na (micro)planificação, continua em ação a acompanhar a transcrição ou redação na página, mantendo viva a possibilidade de alteração das ideias e do texto gerado e surge claramente em foco quando os escreventes procedem a revisão do que foi escrito. A presença de uma componente com funções semelhantes, a componente de Evaluator/Reviser, é também proposta por Chenoweth e Hayes (2003), com base no estudo sobre a relação entre a memória de trabalho e a geração do texto. Os nossos resultados reforçam a necessidade de considerar a ação dessa componente de reformulação no processo de escrita e ligam-na à progressão para o desenvolvimento da escrita.

Os dados analisados neste estudo têm origem na escrita colaborativa, que promove a interação, o confronto de perspetivas, a resolução conjunta de problemas (LOWRY et al., 2004; STORCH, 2005; STURM, 2016). Pode existir um efeito potenciador da componente de reformulação pelo facto de haver vários autores/escritores a trabalhar em conjunto para a construção de um texto único. Contudo, a presença desta componente também está ativa na escrita individual, como mostram técnicas de recolha de dados como a verbalização do pensamento (think-aloud). GarciaDebanc (1986) assinalou precisamente a proximidade entre as interações verbais no âmbito da escrita em grupo e os protocolos resultantes da verbalização do pensamento durante o processo. Se, por um lado, mesmo considerando a presença da reformulação também na escrita individual, pode existir o efeito potenciador na escrita colaborativa, por outro lado, esse efeito potenciador pode transformarse em um instrumento pedagógico, com vista ao próprio desenvolvimento da escrita.

\section{Considerações finais}

A análise do processo de construção de um texto em pequenos grupos por parte de alunos do $2^{\mathrm{O}}$ ao $8^{\mathrm{O}}$ ano de escolaridade revelou a forte presença da reformulação e a evolução crescente dessa presença no intervalo demarcado por esses níveis de escolaridade. Esta conclusão tem implicações para a ação a ser colocada em prática pelos professores para promover o desenvolvimento da escrita dos alunos na primeira década de aprendizagem e de prática da escrita.

Se o processo de escrita analisado fosse marcado essencialmente pela formulação, isto é, pelo tecer de novos segmentos para fazer avançar o texto até ao final, a reformulação teria apenas uma função reparadora e um peso marginal e, sobretudo, decrescente com a progressão dos alunos na escolaridade, no desenvolvimento linguístico e da competência escritural. O processo seria crescentemente marcado pela sucessão de propostas de formulação quase sem necessidade de reformulação. Em princípio, também não haveria vantagem nessa reformulação, para além da função reparadora de inadequações da formulação inicial. Pelo contrário, os resultados encontrados no nosso estudo apontam para uma presença crucial da dimensão de reformulação, após a formulação da proposta inicial. A reformulação surge, assim, como detentora de potencialidades que deverão 
ser transformadas em vantagens (embora a análise das vantagens resultantes das operações de reformulação, designadamente quanto aos resultados para a qualidade textual, não tenha sido o foco do nosso estudo).

À partida, a vantagem da ativação da reformulação é alargar o conjunto de possibilidades para ir construindo cada segmento textual. A existência de diversas possibilidades implica a decisão e a escolha. O desafio consiste em transformar a capacidade de gerar diferentes possibilidades em uma vantagem, o que se projeta em dois sentidos: para a qualidade e a adequação das possibilidades geradas e para a capacidade de decisão e seleção segundo esses critérios de qualidade e adequação.

Uma estratégia pedagógica orientada para esse desafio consiste na promoção da reformulação ligada ao processo de escrita, isto é, no seu decurso. Os alunos podem ser incentivados a procurar possibilidades adicionais, quer em termos de integração de conteúdo, quer em termos da sua expressão. A geração de possibilidades na tarefa que foi objeto deste estudo foi feita entre os alunos do grupo. Uma das vantagens da escrita colaborativa é o facto de os ligeiros desníveis de competência existentes entre os alunos que trabalham em grupo poder mostrar novas possibilidades de realização da tarefa e novas formulações aos alunos habitualmente com menor nível de desempenho (SANTANA, 2007). Esse papel orientador e revelador de novas possibilidades de formulação, segundo os níveis de qualidade linguística e adequação textual desejados, pode ser desempenhado pelo professor. Ele pode ativar a sua própria competência linguística e textual ou tomar como base as formulações encontradas nos textos (ROSE; MARTIN, 2012), para colocar em prática tarefas de escrita e reescrita conjuntas realizadas com a turma.

\section{Referências}

ALAMARGOT, Denis; FAYOL, Michel. Modelling the development of written composition. In: BEARD, Roger; MYHILL, Debra; RILEY, Jenny; NYSTRAND, Martin (org.). Handbook of Writing Development. London: Sage, 2009. p. 23-47. https://doi.org/10.4135/9780857021069.n3

BARBEIRO, Luís. Escrita: Construir a aprendizagem. Braga: Universidade do Minho, 2003.

BARBEIRO, Luís. Os alunos e a expressão escrita. Lisboa: Fundação Calouste Gulbenkian, 1999.

BARBEIRO, Luís. Profundidade do processo de escrita. Educação \& Comunicação, São Paulo, v. 5, p. 64-76, 2001.

BARBEIRO, Luís. What Happens when I Write? Pupils' Writing about Writing. Reading and Writing: An Interdisciplinary Journal, [s. l.], v. 24, n. 7, p. 813-834, 2011. https://doi.org/10.1007/s11145-010-9226-2
BARTHES, Roland. Image-Music-Text. From work to text. London: Fontana, 1977. p. 155-164.

BEREITER, Carl, Scardamalia, Marlene. The Psychology of Written Composition. Hillsdale, New Jersey: Lawrence Erlbaum Associates, 1987.

BERNINGER, Virginia W.; SWANSON, H. Lee, Modifying Hayes and Flower's model of skilled writing to explain beginning and developing writing. In: BUTTERFIELD, Earl C.; CARLSON, Jerry (org.). Children's writing: Toward a process theory of the development of skilled writing. London: JAI Press, 1994, p. 57-81.

BRITTON, James. Shaping at the point of the utterance. In: YOUNG, Richard; LIU, Yameng (org.). Landmark essays on rhetorical invention in writing. New York: Routledge, 1994. p. 147-152.

CALIL, Eduardo. O sentido das palavras e como eles se relacionam com o texto em curso: estudo sobre comentários semânticos feitos por uma díade de alunas de 7 anos de idade. Alfa, Araraquara, v. 60, n. 3, p. 531-555, 2016. https://doi. org/10.1590/1981-5794-1612-4

CHENOWETH, N. Ann, HAYES, John Richard. The Inner Voice in Writing. Written Communication, [s. l.], v. 20, n. 1, p.99-118, 2003. https://doi.org/10.1177/0741088303253572

GARCIA-DEBANC, Claudine. Intérêts des modèles du processus rédactionnel pour une pédagogie de l'écriture. Pratiques, Metz, v. 49, p. 29-56, 1986. https://doi.org/10.3406/ prati.1986.2449

HAYES, John Richard. A new framework for understanding cognition and affect in writing. In: LEVY, C. M.; RANDALL, S. (org.). The science of writing: theories, methods, individual differences, and applications. Mahwah, NJ: Erlbaum, 1996, p. 1-27.

HAYES, John Richard. Kinds of knowledge-telling: Modeling early writing development. Journal of Writing Research, Antwerpen, v. 3, n. 2, 73-92, 2011. https://doi.org/10.17239/ jowr-2011.03.02.1

HAYES, John Richard. Modeling and remodeling writing. Written Communication, [s. 1.], v. 29, n. 3, p. 369-388, 2012. https://doi.org/10.1177/0741088312451260

HAYES, John Richard; FLOWER, Linda. Identifying the organization of writing processes. In: GREGG, L. W.; STEINBERG, E. R. (org.). Cognitive processes in writing. Hillsdale, NJ: Erlbaum, 1980. p.3-30.

HYLAND, Ken. Methods and methodologies in second language writing research. System, v. 59, p. 116-125, 2016. https://doi.org/10.1016/j.system.2016.05.002

KELLOGG, Ronald. Training writing skills: A cognitive developmental perspective. Journal of Writing Research, Antwerpen, v. 1, n. 1, p. 1-26, 2008. https://doi.org/10.17239/ jowr-2008.01.01.1 
LOWRY, Paul Benjamin, CURTIS, Aaron, LOWRY, Michelle René. Building a taxonomy and nomenclature of collaborative writing to improve interdisciplinary research and practice.

Journal of Business Communication, [s. l.], v. 41, n.1, p. 66-99, 2004. https://doi.org/10.1177/0021943603259363

MORÔCO, João. Análise estatística com o SPSS Statistics. 5. ed. Pero Pinheiro: Report Number, 2011.

O'DONNELL, Michael. A dynamic view of choice in writing: Composition as text evolution. In: FONTAINE, Lise; BARTLETT, Tom, O'GRADY, Gerard (org.) Systemic Functional Linguistics: Exploring choice. Cambridge: Cambridge University Press, 2013, p. 247-266. https://doi. org/10.1017/CBO9781139583077.016

PERL, Sondra, EGENDORF, Arthur (1979). The process of creative discovery: Theory, research, and implications for teaching. In: McQUADE, Donald (org.). Linguistics, stylistics, and the teaching of composition. University of Akron: Studies in Contemporary Language, 1979, p. 121-127.

PINTO, Maria da Graça Castro. A escrita académica: um jogo de forças entre a geração de ideias e a sua concretização. Signos, Santa Cruz, v. 41, p.53-71, 2016. https://doi. org/10.17058/signo.v1i1.7325

ROSE, David, MARTIN, James Robert. Learning to write, reading to learn: Genre, knowledge and pedagogy in the Sydney School. London: Equinox, 2012.

SANTANA, Inácia. A aprendizagem da escrita: Estudo sobre a revisão cooperada de texto. Porto: Porto Editora, 2007.

SPINILLO, Alina Galvão. "Por que você alterou isso aqui?" As razões que as crianças adotam quando fazem alterações ao revisar seus textos. Letras de Hoje, Porto Alegre, v. 50, n. 1, p. 32-39, 2015. https://doi.org/10.15448/19847726.2015 .1 .18348

STORCH, Neomy. Collaborative Writing. Product, Process, and Students' Reflections. Journal of Second Language Writing, [s. l.], v. 14, p. 153-173, 2005. https://doi. org/10.1016/j.jslw.2005.05.002

STURM, Afra. Observing writing processes of struggling adult writers with collaborative writing. Journal of Writing Research, Antwerpen, v. 8, n. 2, 301-344, 2016. https://doi. org/10.17239/jowr-2016.08.02.05

Recebido em: 28/10/2018.

Aprovado em: 22/5/2019.

Publicado em: 5/11/2019.

\section{Autores:}

LUÍS BARBEIRO

Doutor em Educação, Metodologia de Ensino do Português e agregado em Ciências da Educação - Literacias e Ensino do Português, pela

Universidade do Minho, Portugal. Escola Superior de Educação e Ciências Sociais (ESECS). Instituto Politécnico de Leiria, Leiria, Portugal.

Orcid: https://orcid.org/0000-0001-5798-2904

E-mail: luis.barbeiro@ipleiria.pt

Endereço: Campus 1 Rua Dr. João Soares Apt 4045

2411-901, Leiria, Portugal 